\title{
Examining frailty and multimorbidity in nursing research of older emergency department patients
}

\author{
Fabrice Mowbray', PhD(c), RN \\ Department of Health Research Methods, Evidence and Impact, McMaster University
}

$\mathrm{E}$

mergency nurses and departments are currently challenged to adapt traditional models of care to better accommodate the complex physical and psychosocial needs of the growing geriatric population (American College of Emergency Physicians et al., 2014; Bullard et al., 2017). Health service demand and emergency department (ED) use is projected to parallel population ageing, considering geriatric syndromes drive patient-important health outcomes and service use in older adults (Costa et al., 2014; Mowbray, Zargoush, et al., 2020). Geriatric syndromes are physical or psychosocial conditions with complex and multifaceted etiologies frequently found in older persons, including functional decline, cognitive impairment, and frailty (Inouye et al., 2007).

Geriatric syndromes are infrequently assessed or documented by emergency healthcare providers and researchers (Carpenter, Griffey, et al., 2011), yielding a biased and limited understanding of the patient and system factors that influence patient-important outcomes in older ED patients. Worse patient outcomes and a greater risk for under-triage in older ED cohorts (Aminzadeh \& Dalziel, 2002; Platts-Mills et al., 2010) underscore the need for additional geriatric and vulnerability assessment to accurately triage, assess and care for older adults seeking emergency care (Carpenter \& Mooijaart, 2020).

Frailty and multimorbidity are two succinct and informative geriatric-sensitive measures to consider in clinical and academic settings. These measures can be screened for within minutes and provide foreknowledge of patient complexity and vulnerability to inform clinical decision-making (Carpenter, Bassett, et al., 2011; Elliott et al., 2017, 2020; Sasseville et al., 2019). Policymakers and health researchers value and benefit from the assessment and documentation of these measures, as they inform policy development and population-level health system planning (Griffith et al., 2018; Muscedere et al., 2016).
Frailty is a multidimensional syndrome characterized by a heightened vulnerability to adverse health events and a diminished physiologic reserve inhibiting homeostatic recovery from stressors (Fried et al., 2001; Rockwood et al., 2005). Age has proven to be a strong predictor of health service use and outcomes in the general population. However, in older ED patients, the prognostic value of age is limited and likely confounded by frailty and geriatric complexity (Mowbray, Brousseau, et al., 2020). Frailty is most commonly measured using one of two methods, a health deficit accumulation index or a phenotypic model.

Health deficit accumulation indices estimate frailty by dividing the current number of health deficits over all possible health deficits measured and presented as decimals (Rockwood et al., 2005; Rockwood \& Mitnitski, 2012). On the other hand, phenotypic measurements determine frailty by screening for specific assessment indicators or formal support needs, like assistance with walking (Fried et al., 2001). Phenotypic models are more commonly used in clinical practice settings, likely due to their ease of implementation. However, health deficit accumulation models, like the ED frailty index (Brousseau et al., 2018), may be better suited for research purposes, as they allow investigators to examine the full granularity of data. Additionally, when utilizing a health deficit accumulation model to operationalize frailty, it is recommended that nursing and emergency researchers leave the index in its natural continuous state when possible to avoid (i) a loss of information, (ii) an increased type-one error rate (i.e., false-positive findings), and (iii) the arbitrary creation of a dichotomy in the data (e.g., frail versus not frailty), which often results in decreased statistical power and generalizability of study findings (Altman \& Royston, 2006; Austin \& Brunner, 2004).

Multimorbidity is prevalent in older persons and is defined as the coexistence of two or more chronic diseases (Marengoni et al., 2011). Like frailty, multimorbidity is strongly associated with 
health service use and outcomes in older persons (Marengoni et al., 2011). While these conditions often exist in parallel, their measures can diverge significantly, suggesting that they offer unique prognostic value when determining patient outcomes and clinical therapies. For example, a patient with hypertension, hypercholesteremia, and gout, would be classified as multimorbid. However, it is unlikely they would be categorized as more frail or vulnerable than patients with stage III congestive heart failure as the sole diagnosis. This illustration suggests that frailty is influenced more by the severity and interaction of chronic health conditions than the count.

Information on patient diagnoses can be found in virtually all medical and administrative records, facilitating retrospective calculation of multimorbid status. This likely explains why studies are more prone to evaluate and report associations with multimorbidity in older persons (Griffith et al., 2018). On the other hand, frailty often requires the direct assessment of geriatric syndromes and functional capacity by a nurse or healthcare provider in the ED to support valid measurement (Hubbard \& Story, 2014). Despite strong recommendations for frailty and vulnerability screening in the ED by the American College of Emergency Physicians (ACEP), the American Geriatric Society (AGS), the Emergency Nursing Association (ENA), and the Society for Academic Emergency Medicine (SAEM) (American College of Emergency Physicians et al., 2014), few emergency departments or institutions have adopted this practice as a standard of care. A lack of data and challenges in the retrospective calculation are barriers that may explain why frailty is often missing from ageing and emergency research.

The examination of frailty is essential to facilitate accurate statistical estimates and a contextualized understanding of the patient profile and ED-specific outcomes. Where possible, nursing and emergency researchers focused on geriatric care should aim to collect or analyze data on patient frailty, using one of the many valid instruments available, such as the Clinical Frailty Scale (Rockwood et al., 2005; Theou et al., 2021), Fried's phenotypic model (Fried et al., 2001), or the ED Frailty Index (Brousseau et al., 2018), to name a few. If interested in the unique prognostic value of frailty or multimorbidity, uncontaminated measures are needed to prevent overfit statistical models and poor external validity (Theou \& Searle, 2018). In other words, it is essential to ensure that the selected frailty measure does not take into account co-morbid status and vice versa. The author offers an additional word of caution against frailty measures that base calculations on a single assessment, diagnosis, or laboratory value (e.g., grip strength or sarcopenia), as these measures do not capture the multidimensional nature of frailty.

Emergency nurses and researchers should also avoid the use of frailty scales that leverage documented diagnoses alone to determine frailty status, such as the Hospital Frailty Risk Score (Gilbert et al., 2018). While diagnoses are a convenient metric to leverage, there are concerns in administrative and hospital data regarding the accuracy of diagnostic and procedural codes (O'Malley et al., 2005). Certain diagnostic codes and procedures are directly linked with quality metrics, billing and other clinician-important outcomes and, therefore, are more accurately documented. Additionally, frailty and other geriatric syndromes are less commonly assessed and likely underrepresented in medical records, highlighting a potential selection bias for retrospective data abstraction.

In summary, emergency nurses and researchers should aim to assess, or measure, frailty and multimorbidity in their clinical and academic practice, as these measures have exceptional prognostic value. Age alone is an uninformative characteristic in older persons. As the largest body of emergency clinicians, nurses provide the majority of direct bedside care and documentation for older ED patients, highlighting a unique opportunity for emergency nursing research and leadership moving forward.

\section{REFERENCES}

Altman, D. G., \& Royston, P. (2006). The cost of dichotomising continuous variables. British Medical Journal, 332(7549), 1080.

American College of Emergency Physicians, American Geriatrics Society, Emergency Nurses Association, Society for Academic Emergency Medicine, \& Geriatric Emergency Department Guidelines Task Force. (2014). Geriatric emergency department guidelines. Annals of Emergency Medicine, 63(5), e7-25. https:// doi.org/10.1016/j.annemergmed.2014.02.008

Aminzadeh, F., \& Dalziel, W. B. (2002). Older adults in the emergency department: A systematic review of patterns of use, adverse outcomes, and effectiveness of interventions. Annals of Emergency Medicine, 39(3), 238-247. https://doi.org/10.1067/ mem.2002.121523

Austin, P. C., \& Brunner, L. J. (2004). Inflation of the type I error rate when a continuous confounding variable is categorized in logistic regression analyses. Statistics in Medicine, 23(7), 1159-1178. https://doi.org/10.1002/sim.1687

Brousseau, A. A., Dent, E., Hubbard, R., Melady, D., Émond, M., Mercier, É., Costa, A. P., \& Multinational Emergency Department Study. (2018). Identification of older adults with frailty in the Emergency Department using a frailty index: Results from a multinational study. Age and Ageing, 47(2), 242-248. https://doi. org/10.1093/ageing/afx168
Bullard, M. J., Melady, D., Emond, M., Musgrave, E., Unger, B., van der Linde, E., Grierson, R., Skeldon, T., Warren, D., \& Swain, J. (2017). Guidance when applying the Canadian Triage and Acuity Scale (CTAS) to the geriatric patient: Executive summary. Canadian Journal of Emergency Medicine, 19(S2), S28-S37. https://doi. org/10.1017/cem.2017.363

Carpenter, C. R., Bassett, E. R., Fischer, G. M., Shirshekan, J., Galvin, J. E., \& Morris, J. C. (2011). Four sensitive screening tools to detect cognitive dysfunction in geriatric emergency department patients: Brief Alzheimer's Screen, Short Blessed Test, Ottawa 3DY, and the caregiver-completed AD8. Academic Emergency Medicine, 18(4), 374-384. https://doi.org/10.1111/j.1553-2712.2011.01040.x

Carpenter, C. R., Griffey, R. T., Stark, S., Coopersmith, C. M., \& Gage, B. F. (2011). Physician and nurse acceptance of technicians to screen for geriatric syndromes in the emergency department. Western Journal of Emergency Medicine, 12(4), 489-495. https:// doi.org/10.5811/westjem.2011.1.1962

Carpenter, C. R., \& Mooijaart, S. P. (2020). Geriatric Screeners 2.0: Time for a paradigm shift in emergency department vulnerability research. Journal of the American Geriatrics Society, 68(7), 14021405. https://doi.org/10.1111/jgs.16502

Costa, A. P., Hirdes, J. P., Heckman, G. A., Dey, A. B., Jonsson, P. V., Lakhan, P., Ljunggren, G., Singler, K., Sjostrand, F., Swoboda, 
W., Wellens, N. I. H., \& Gray, L. C. (2014). Geriatric syndromes predict postdischarge outcomes among older emergency department patients: Findings from the interRAI Multinational Emergency Department Study. Academic Emergency Medicine, 21(4), 422-433. https://doi.org/10.1111/acem.12353

Elliott, A., Phelps, K., Regen, E., \& Conroy, S. P. (2017). Identifying frailty in the emergency department - Feasibility study. Age and Ageing, 46(5), 840-845. https://doi.org/10.1093/ageing/afx089

Elliott, A., Taub, N., Banerjee, J., Aijaz, F., Jones, W., Teece, L., van Oppen, J., \& Conroy, S. (2021). Does the Clinical Frailty Scale at triage predict outcomes from emergency care for older people? Annals of Emergency Medicine, 77(6), 620-627. https://doi. org/10.1016/j.annemergmed.2020.09.006

Fried, L. P., Tangen, C. M., Walston, J., Newman, A. B., Hirsch, C., Gottdiener, J., Seeman, T., Tracy, R., Kop, W. J., Burke, G., McBurnie, M. A., \& Cardiovascular Health Study Collaborative Research Group. (2001). Frailty in older adults: Evidence for a phenotype. The Journals of Gerontology. Series A, Biological Sciences and Medical Sciences, 56(3), M146-156. https://doi.org/10.1093/ gerona/56.3.m146

Gilbert, T., Neuburger, J., Kraindler, J., Keeble, E., Smith, P., Ariti, C., Arora, S., Street, A., Parker, S., Roberts, H. C., Bardsley, M., \& Conroy, S. (2018). Development and validation of a Hospital Frailty Risk Score focusing on older people in acute care settings using electronic hospital records: An observational study. Lancet, 391(10132), 1775-1782. https://doi.org/10.1016/ S0140-6736(18)30668-8

Griffith, L. E., Gruneir, A., Fisher, K. A., Nicholson, K., Panjwani, D., Patterson, C., Markle-Reid, M., Ploeg, J., Bierman, A. S., Hogan, D. B., \& Upshur, R. (2018). Key factors to consider when measuring multimorbidity. Journal of Comorbidity, 8(1), 2235042X18795306. https://doi.org/10.1177/2235042X18795306

Hubbard, R. E., \& Story, D. A. (2014). Patient frailty: The elephant in the operating room. Anaesthesia, 69(Suppl 1), 26-34. https://doi. org/10.1111/anae. 12490

Inouye, S. K., Studenski, S., Tinetti, M. E., \& Kuchel, G. A. (2007). Geriatric syndromes: Clinical, research, and policy implications of a core geriatric concept. Journal of the American Geriatrics Society, 55(5), 780-791. https://doi. org/10.1111/j.1532-5415.2007.01156.x

Marengoni, A., Angleman, S., Melis, R., Mangialasche, F., Karp, A., Garmen, A., Meinow, B., \& Fratiglioni, L. (2011). Aging with multimorbidity: A systematic review of the literature. Ageing Research Reviews, 10(4), 430-439. https://doi.org/10.1016/j. arr.2011.03.003

Mowbray, F., Brousseau, A. A., Mercier, E., Melady, D., Émond, M., \& Costa, A. P. (2020). Examining the relationship between triage acuity and frailty to inform the care of older emergency department patients: Findings from a large Canadian multisite cohort study. CJEM, 22(1), 74-81. https://doi.org/10.1017/ cem.2019.432

Mowbray, F., Zargoush, M., Jones, A., de Wit, K., \& Costa, A. (2020). Predicting hospital admission for older emergency department patients: Insights from machine learning. International Journal of Medical Informatics, 140, 104163. https://doi.org/10.1016/j. ijmedinf.2020.104163

Muscedere, J., Andrew, M. K., Bagshaw, S. M., Estabrooks, C., Hogan, D., Holroyd-Leduc, J., Howlett, S., Lahey, W., Maxwell, C., McNally, M., Moorhouse, P., Rockwood, K., Rolfson, D., Sinha, S., Tholl, B., \& Canadian Frailty Network (CFN). (2016). Screening for frailty in Canada's health care system: A time for action. Canadian Journal on Aging, 35(3), 281-297. https://doi.org/10.1017/ S0714980816000301

O’Malley, K. J., Cook, K. F., Price, M. D., Wildes, K. R., Hurdle, J. F., \& Ashton, C. M. (2005). Measuring diagnoses: ICD code accuracy. Health Services Research, 40(5 Pt 2), 1620-1639. https://doi. org/10.1111/j.1475-6773.2005.00444.x

Platts-Mills, T. F., Travers, D., Biese, K., McCall, B., Kizer, S., LaMantia, M., Busby-Whitehead, J., \& Cairns, C. B. (2010). Accuracy of the Emergency Severity Index triage instrument for identifying elder emergency department patients receiving an immediate lifesaving intervention. Academic Emergency Medicine, 17(3), 238243. https://doi.org/10.1111/j.1553-2712.2010.00670.x

Rockwood, K., \& Mitnitski, A. (2012). How might deficit accumulation give rise to frailty? The Journal of Frailty \& Aging, 1(1), 8-12. https://doi.org/10.14283/jfa.2012.2

Rockwood, K., Song, X., MacKnight, C., Bergman, H., Hogan, D. B., McDowell, I., \& Mitnitski, A. (2005). A global clinical measure of fitness and frailty in elderly people. Canadian Medical Association Journal, 173(5), 489-495. https://doi.org/10.1503/cmaj.050051

Sasseville, M., Smith, S. M., Freyne, L., McDowell, R., Boland, F., Fortin, M., \& Wallace, E. (2019). Predicting poorer health outcomes in older community-dwelling patients with multimorbidity: Prospective cohort study assessing the accuracy of different multimorbidity definitions. BMJ Open, 9(1), e023919. https:// doi.org/10.1136/bmjopen-2018-023919

Theou, O., Pérez-Zepeda, M. U., van der Valk, A. M., Searle, S. D., Howlett, S. E., \& Rockwood, K. (2021). A classification tree to assist with routine scoring of the Clinical Frailty Scale. Age and Ageing, 50(4), 1406-1411. https://doi.org/10.1093/ageing/ afab006

Theou, O., \& Searle, S. D. (2018). Using frailty tools as prognostic markers in patients who are acutely ill. Canadian Medical Association Journal, 190(7), E182-E183. https://doi. org/10.1503/cmaj. 170902 